\title{
Automated Check Processing
}

\author{
September 1, 1967 Deadline Approaching
}

c

HECKS CLEARED through any Federal Reserve Bank after September 1, 1967 must have the routing symbol-transit number of the bank on which it is drawn imprinted with E-13B characters in magnetic ink. This is MICR (Magnetic Ink Character Recognition) encoding. This routing number is that set of odd-looking numbers printed along the lower edge on the left side of the check. If a check does not meet this requirement after September 1, 1967, it will no longer be handled by the Federal Reserve Bank as a check. Such checks will suffer delays in collection and could result in collection charges.

Since its introduction in 1956 by the American Bankers Association, the MICR program has revised and revitalized the entire check collection system. The MICR program is the most practical and efficient means devised thus far to handle the swelling volume of checks. Not only does it benefit the banking industry, but more importantly, it improves the checking service that banks provide for their customers.

When automated check handling first came to banking, the Federal Reserve System issued regulations that specified certain requirements a check would have to meet in order to be effectively handled on high-speed equipment as a cash item. A cash item, or conforming item, is capable of talking a common machine language and experiences a shorter collection time than a noncash item.

After September 1 , if the bank's routing symboltransit number does not appear in magnetic ink on the check prior to receipt by the Fed, it will be treated as a noncash item. Noncash items are not processed as quickly because special handling is required. Also, the sending bank does not receive credit for it until the Federal Reserve Bank receives payment from the bank on which it is drawn, which means a longer collection time.

Items sent to the Federal Reserve Bank for collection, fully encoded with magnetic ink, can now be processed at a speed of 60,000 items per hour. If these items do not conform to the computer's specifications, they are then processed by low-speed equipment at an approximate rate of only 1,500 items per hour, or sorted by hand at an even slower rate which lengthens processing time considerably.

For the past few years, the American Bankers Association, check-clearing correspondent commercial banks, and the Federal Reserve System have been urging that all checks bear the home bank's MICR routing symbol-transit number. A survey made during January 1967 disclosed that on a nationwide basis, almost 3 per cent of all items received by the Federal Reserve System did not bear the routing symbol-transit number in magnetic ink. In the St. Louis District, over 8 per cent of the checks did not conform. A survey in April (table) showed some improvement; nationwide, only 2 per cent of all items reviewed did not conform, compared with 6.4 per cent in the St. Louis District.

\section{Items Not Bearing MICR Routing Symbol}

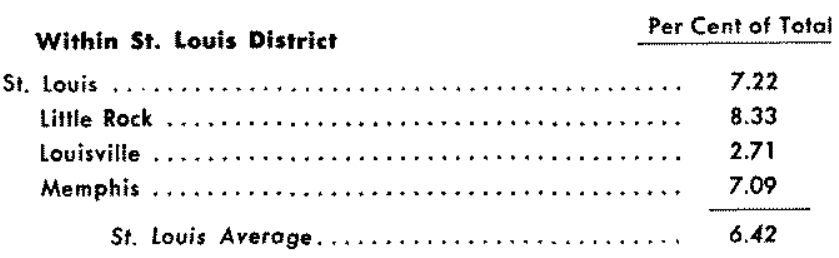

\section{All Districts}

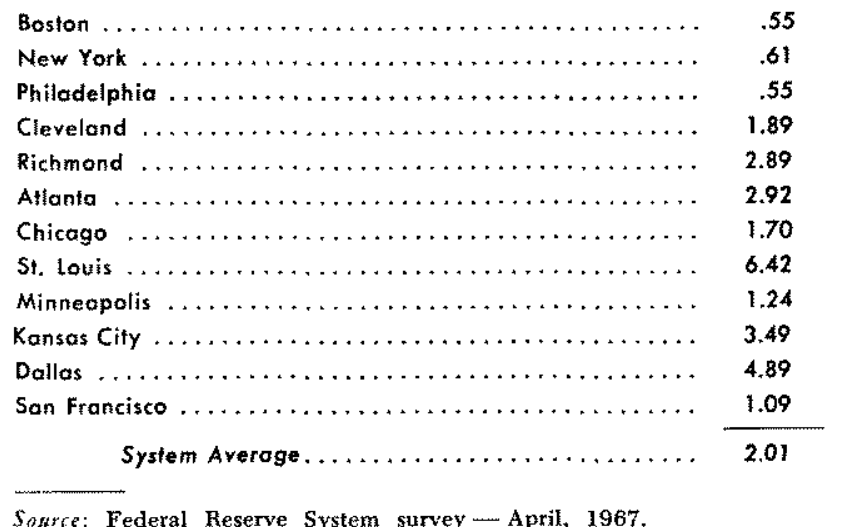


Personal and corporate checks accounted for almost two-thirds of the items reviewed that did not contain the MICR routing designation. Other checks which are also considered "headache" items and present problems for automatic handling are universal checks. These are checks on which the name of the bank has not been printed. They are usually made available by stores and other businesses for their forgetful customers. The customer fills out the check and writes in the name of the bank upon which it is drawn. Eventually customers who use a universal check may be charged a substantial fee.

The largest "headache" item for the computer is the so-called scratched check, on which the name of the bank is printed but scratched out and the name of another bank written in. When the computer scans the check it will read the MICR routing number of the bank scratched out and sort the check to that bank and not to the bank that was written in. This causes considerable missending, increases costs, and effects delays in collection.

The banking and business communities have cooperated in making an effort to eliminate non-conforming items prior to the September 1 deadline. Intermittently since April this year, the Federal Reserve Bank of St. Louis has been attaching labels to checks which will no longer be handled as checks after September 1, 1967. In addition, placards have been provided for display in banks, retail stores, shopping centers, and other locations where large numbers of personal checks are cashed. Articles and advertisements have appeared in various publications and news media. Speeches have been given at meetings of businessmen and bankers.

The purpose of all this promotion is to make the millions of check users aware of the September 1 deadline and what it means to them. The banking industry is on the threshold of a new era. The MICR program is the beginning of automated check handling and deposit accounting.

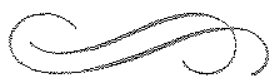

\author{
SUBSCRIPTIONS to this bank's REview are available to the public without \\ charge, including bulk mailings to banks, business organizations, educational \\ institutions, and others. For information write: Research Department, Federal \\ Reserve Bank of St. Louis, P. O. Box 442, St. Louis, Missouri 63166.
}

